Editorial

\title{
Journal of cardiology and current research: new and unique medical journal
}

\section{Editorial}

The heart is well known by most of the people as the organ of life and love. We, as doctors are concerned with its health, but can do nothing regarding love and its feelings. Increasing complexity and subspecialization in Cardiology Science, made it difficult for the general doctors to keep fully informed of recent advances in the medical and surgical management of cardiac diseases. Also, the heart challenges all doctors to obtain a diagnosis and institute proper therapy for its various pathological conditions. Research work to reveal the secrets of the heart diseases and get their proper management is taking a lot of time and effort from doctors working with pleasure and interest in that field. With all these ideas in mind, The Journal of Cardiology and Current Research was cited to be a shining star in the cardiology field. The contributors will cover these aspects progressively and comprehensively. Because of the rapid progress of this specialty, the journal will appear at frequent intervals to let each new volume a true reflection of recent advances and research in the field of Cardiology Science. That is, simply because it is not possible to encompass in one volume all the advances that have occurred worldwide.

The journal and its contributors will cover all about diagnosis, treatment and recent researches in cardiology for better health of cardiac patients and in turn, the human beings. We hope that practicing clinicians will find a reasonable spread of interest is provided in each volume of the journal.

\author{
Volume I Issue I - 2014 \\ Mohamed Abdelalim Sayed Ahmed \\ Department of Cardio Thoracic Surgery, Cairo University, Egypt \\ Correspondence: Mohamed Abdelalim Sayed Ahmed, \\ Department of Cardio Thoracic Surgery, Faculty of Medicine, \\ Cairo University, Egypt, Tel 002-02-33802784, \\ Email cardio_thoracic201 I@yahoo.com \\ Received: May 10, 2014 | Published: May 12, 2014
}

Lastly, it is a great honor to start this journal to join other medical journals all over the world. Also, I wish to express my deepest appreciations to all personnel who contributed in the citation of such a good, scientific and beneficial journal. Am sure their work will succeed in stimulating the interest of all doctors to share in solving the problems of the cardiac diseases and will supply the journal with their research work for better cardiac care and patients' health.

\section{Acknowledgement}

None.

\section{Conflicts of interest}

Authors declare that there is no conflict of interest. 